\title{
PREDIKSI MINAT KONSUMEN TERHADAP PRODUK PERUSAHAAN DIRECET SELLING TIANSHI MENGGUNAKAN ARTIFICIAL NEURAL NETWORK (ANN)
}

\author{
Khairunnisa Samosir \\ Ilmu Komputer, Universitas Graha Nusantara Padangsidimpuan \\ email: khairunnisasamosir01@gmail.com
}

\begin{abstract}
Tiansi is a company that markets health products. This company has difficulty predicting people's interest in products that are in high demand. By knowing precisely the consumer interest in the product, it will increase sales. The research aims to predict consumer interest in Tiansi products appropriately. The method used is one of the Artificial Neural Network (ANN) techniques, namely Backpropagation with Momentum. The sales data tested were sourced from Stockist 319 Padang. The results of this research that can precisely determine consumer interest are architecture 5-2-1 and 5-3-1. So that this research is very helpful in the procurement of goods to increase the value of sales.
\end{abstract}

Keywords: Artificial neural network, backpropagation, consumer interest rates, predictions.

\begin{abstract}
Abstrak: Tiansi merupakan sebuah perusahaan yang memasarkan produk-produk kesehatan. Perusahaan ini mengalami kesulitan dalam memprediksi minat masyarakat terhadap produk yang sangat diminati. Dengan mengetahui dengan tepat minat konsumen terhadap produknya, maka akan dapat meningkatkan penjualan. Penelitian ini bertujuan untuk memprediksi minat konsumen terhadap produk Tiansi dengan tepat. Metode yang digunakan salah satu teknik Artificial Neural Network (ANN), yaitu Backpropagation dengan Momentum. Data penjualan yang diuji bersumber dari Stokist 319 Padang. Hasil dari penelitian ini yang dapat dengan tepat menentukan minat konsumen adalah arsitektur 5-2-1 dan 5-3-1. Sehingga penelitian ini sangat membantu sekali dalam pengadaan barang untuk meningkatkan nilai penjualan.
\end{abstract}

Kata kunci: Jaringan Syaraf Tiruan, Backpropagation, prediksi, minat konsumen, penjualan.

\section{PENDAHULUAN}

Penjualan langsung atau direct selling (DS) merupakan metode penjualan barang kepada konsumen dengan cara langsung oleh jaringan pemasaran yang dikembangkan oleh mitra usaha. DS dapat memasarkan produk langsung ke konsumen secara eceran di luar lokasi penjual [1].Data
Asosiasi Penjual Langsung Indonesia (APLI) mencatat total penjualan pada DS selalu meningkat. Pada tahun 1999 mencapai nilai Rp. 2,09 triliun, tahun 2002 dengan nilai Rp. 4,17 triliun dan tahun 2003 dengan nilai Rp. 6,2 triliun. Peningkatan ini diiringi juga oleh pertumbuhan jumlah distributor.Pada tahun 1999 berjumlah 3.974.000 orang, 
DOI: https://doi.org/10.33330/jurteksi.v7i1.xxx

Available online at http://jurnal.stmikroyal.ac.id/index.php/jurteksi

pada tahun 20024.765 .000 orang, dan tahun 2003 meningkat menjadi 5.472.000 orang.

Pada saat ini terdapat lebih dari 200 perusahaan yang bergerak pada bisnis DS sedangkan yang terdaftar sebagai anggota APLI sebanyak 63 perusahaan. Sebagian besar perusahaan DS yang beroperasi di Indonesia adalah dalam menjual produk makanan, kesehatan, dan kecantikan.

Dalam aktivitas DS, pemasaran produk menjadi bagian yang sangat vital. Untuk mengukur perkembangannya perlu dilakukan dengan berbagai cara dan media. Tujuannya adalah merubah ketertarikan konsumen menjadi kebutuhan sehingga terjadi pemesanan ulang (repeat order) yang tinggi.Langkah yang dilakukan adalah dalam bentuk pertemuan kecil (home meeting), seminar dan dalam bentuk penyebaran informasi melalui kaset serta compact disc.

Agar pemasaran ini tepat sasaran, maka perlu dilakukan penilai minat konsumen mengenai produk yang dipasarkan. Langkah ini dapat menekan biaya dan juga meningkatkan penjualan karena pemasaran menjadi tepat kepada peminat dari produk tersebut. Banyak metode yang dapat dilakukan untuk mengetahui minat konsumen dan yang umum digunakan adalah jaringan saraf tiruan atau Artificial Neural Network (ANN). Seperti penelititan yang dilakukan oleh Lawrence pada tahun 1977 dalam memprediksi harga pada pasar modal dengan menggunakan ANN [2]. Penelitian ini dapat melakukan pemetaan non linier antara data masukan dan keluaran pemasaran produk pada konsumen. Dalam melakukan peramalan, metode ANN lebih baik dapat dihandalkan terhadap proses yang berulang-ulang [3]. Dalam peramalan penjualan produksi coklat, maka ANN dapat memberikan hasil yang lebih valid dan akurat [4].

Selain itu, ANNmemiliki kemampuan dalam generalisasi data. Kemampuan ini sangat dibutuhkan dalam kasus peramalan dalam prediksi. Kemampuan ini dibutuhkan karena banyaknya kandungan noise atau data tidak lengkap terhadap data yang diolah [5].Pengembangkan metode ANN dapat diterapkan dalam fungsi basis radial. Fungsi ini dapat diimplementasikan dengan menggunakan program computer. Sehingga dapat lebih tepat dalam menyelesaikan sejumlah proses perhitungan yang banyak selama proses pembelajaran [6].

Untuk itu dilakukan penelitian ini dalam memprediksi minat konsumen dalam DS. Tujuannya adalah mempermudah manajemen dalam melakukan prediksi minat konsumen terhadap produkproduk perusahaan Tianshi. Banyak parameter yang digunakan, seperti harga produk, kualitas, distribusi produk, jumlah sertifikasi, dan kuantitas. Sehingga manager perusahaan dapat meningkatkan penjualan dengan prediksi tepat terhadap minat konsumen dalam memenuhi kebutuhannya terhadap produksi Tiensi.

\section{METODE}

Penelitian ini mengolah data konsumen produksi Tiensi dengan tahapan-tahapan proses. Setiap tahapan memiliki ketergantungan proses dengan tahapan lainnya agar menghasilkan prediksi yang valid. Tahapan ini disajikan pada Gambar 1. 


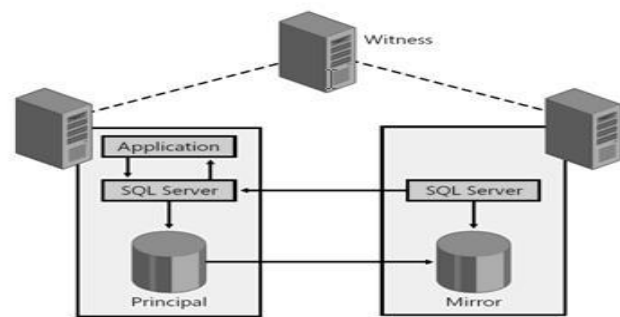

Gambar 1. Tahapan Proses Prediksi Minat Konsumen

Pertama sekali dilakukan pengumpulan data konsumen pada Stokist 319 Tiensi Padang terhadap produk Tiensi. Banyak konsumen yang di data adalah 20 orang. Data ini dikelompokan berdasarkan kriteria minat konsumen, yaitu sangat suka, suka, bias, tidak suka dan tidak tahu. Jumlah setiap kriteria disajikan pada Tabel 1.

Agar masukan dapat dilatih, tabel diubah kedalam bentuk matriks $\mathrm{P}$ berukuran $5 \times 14$ dan data sisanya digunakan untuk pengujian dengan matriks U berukuran 5x6. Hasil keluaran (target) yang diinginkan berupa minat konsumen yang terbagi menjadi 2 pola, yaitu Prediksi minat buruk (0) dan Prediksi minat baik (1). Pada pola (0) taksiran antara 0,001 sampai dengan 0,499 dan pola (1) taksiran antara 0,500 sampai dengan 1,000 .

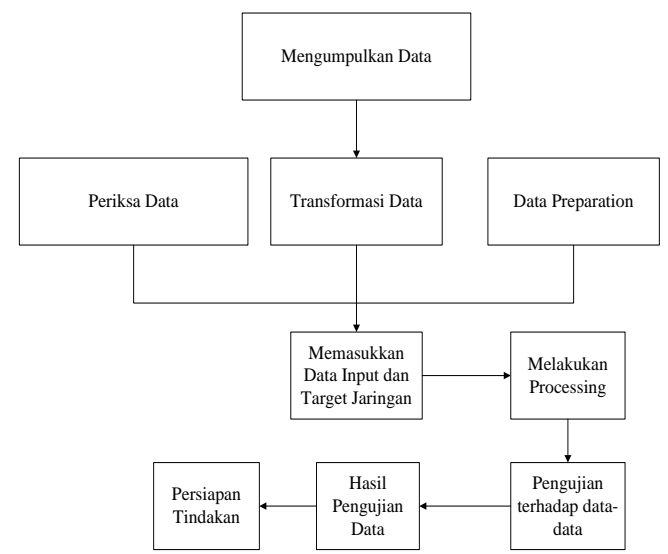

Gambar 1. Kerangka Kerja Penelitian Tabel 1. Data Konsumen Produk Tiensi

\begin{tabular}{cccccc}
\hline No & $\begin{array}{l}\text { Sangat } \\
\text { Suka }\end{array}$ & Suka & $\begin{array}{l}\text { Bia } \\
\text { s }\end{array}$ & $\begin{array}{l}\text { Tidak } \\
\text { Suka }\end{array}$ & $\begin{array}{l}\text { Tidak } \\
\text { Tahu }\end{array}$ \\
\hline 1 & 31 & 26 & 20 & 15 & 11 \\
\hline 2 & 35 & 30 & 25 & 18 & 13 \\
\hline 3 & 34 & 28 & 23 & 16 & 15 \\
\hline 4 & 34 & 30 & 24 & 19 & 14 \\
\hline 5 & 33 & 28 & 23 & 20 & 15 \\
\hline 6 & 32 & 28 & 25 & 18 & 13 \\
\hline 7 & 35 & 30 & 23 & 16 & 15 \\
\hline 8 & 31 & 29 & 25 & 15 & 12 \\
\hline 9 & 33 & 30 & 25 & 16 & 13 \\
\hline 10 & 35 & 26 & 23 & 15 & 11 \\
\hline 11 & 34 & 29 & 20 & 17 & 15 \\
\hline 12 & 33 & 26 & 24 & 15 & 14 \\
\hline 13 & 31 & 30 & 23 & 19 & 15 \\
\hline 14 & 34 & 28 & 24 & 20 & 12 \\
\hline 15 & 35 & 29 & 25 & 19 & 12 \\
\hline 16 & 30 & 26 & 23 & 20 & 14 \\
\hline 17 & 34 & 30 & 21 & 19 & 11 \\
\hline 18 & 30 & 28 & 22 & 20 & 15 \\
\hline 19 & 35 & 29 & 25 & 15 & 11 \\
\hline 20 & 31 & 28 & 22 & 18 & 12 \\
\hline Sur
\end{tabular}

Sumber : Data Transaksi Stockist 319

Padang

2. Periksa Data

Peneliti dapat memeriksa kembali data apa yang dibutuhkan dan data yang tidak dibutuhkan sehingga dapat mempermudah peneliti dalam membuat sebuah laporan pengujian dengan data minat konsumen.

\section{Transformasi Data}

Data yang dilakukan dengan tujuan mengubah skala pengukuran data asli menjadi bentuk lain sehingga data dapat memenuhi asumsi-asumsi yang mendasari analisis ragam.

\subsection{Data Preparation}

Peneliti dapat membuat data mentah menjadi yang berkualitas tanpa dibuat yang tidak asli sehingga mempermudah seorang konsumen untuk melihat data asli.

2.5. Memasukkan Data Input dan Target Jaringan

Data input yang telah dikumpulkan, peneliti harus dapat menargetkan data 
DOI: https://doi.org/10.33330/jurteksi.v7i1.xxx

Available online at http://jurnal.stmikroyal.ac.id/index.php/jurteksi

yang telah ada akan ditargetkan kejaringan mana yang akan ditentukan.

2.6 Melakukan Processing

Peneliti dapat memberikan manfaat kepada konsumen dengan membantu konsumen untuk melakukan lebih banyak tugas dan juga kegiatan dengan mudah dan praktis.

2.7 Pengujian Terhadap Data-data

Pengujian terhadap data-data terhadap konsumen apakah sangat suka, suka, tidak suka dan tidak tahu akan tampil didalam sebuah program yang menggunakan Aplikasi Matlab.

2.8 Hasil Pengujian data

Hasil Pengujian Data adalah untuk membantu mengatasi tingkat penanganan minat konsumen dalam perusahaan direct selling apakah sangat suka, suka, tidak suka atau tidak tahu.

2.9 Persiapan Tindakan

Setelah tingkat penanganan dilanjutkan, selanjutnya persiapan pelaksanaan tindakan dilakukan oleh User. Dimana sistem sudah mengeluarkan hasil prediksi minat konsumen dan persiapan pelaksanaan tindakan selanjutnya yang akan dilakukan.

\section{HASIL DAN PEMBAHASAN}

Pengujian yang dilakukan pada penelitian ini dengan menggunakan arsitektur jaringan 5-2-1 dimana artinya adalah unit input 5, unit hidden layer 2 dan unit output 1 . Tujuan pengujian ini adalah untuk membuktikan bahwa arsitektur jaringan yang dibangun terutama pada kasus prediksi minat konsumen dapat diaplikasikan pada perangkat lunak yang dipilih yaitu Matlab. Pengujian aplikasi Jaringan Syaraf Tiruan dengan arsitektur 5-2-1 dibantu dengan bahasa pemrograman matlab dilakukan untuk melihat perban- dingan target yang diinginkan dengan hasil pembelajaran pada JST, sebelum melakukan ujicoba terlebih dahulu variabel input dan variabel output dikelompokkan, yang mana variabel input-nya adalah faktor-faktor yang mempengaruhi peramalan minat konsumen.

B. Data Input dan Target

Setelah ditentukan nilai variabel, selanjutnya data-data pengaruh minat konsumen yang terdapat pada semua variabel diganti dengan nilai-nilai yang didapat berdasarkan data konsumen dan disusun ke dalam sebuah tabel seperti tabel 1. berikut :

Tabel 2. Data Konsumen

\begin{tabular}{cccccc}
\hline No & $\mathrm{X}_{1}$ & $\mathrm{X}_{2}$ & $\mathrm{X}_{3}$ & $\mathrm{X}_{4}$ & $\mathrm{X}_{5}$ \\
& (Sanga & (Suk & (Bias & (Tidak & (Tidak \\
& t Suka) & a) & a) & Suka) & Tahu)
\end{tabular}

\begin{tabular}{cccccc}
\hline 1 & 31 & 26 & 20 & 15 & 11 \\
\hline 2 & 35 & 30 & 25 & 18 & 13 \\
\hline 3 & 34 & 28 & 23 & 16 & 15 \\
\hline 4 & 34 & 30 & 24 & 19 & 14 \\
\hline 5 & 33 & 28 & 23 & 20 & 15 \\
\hline 6 & 32 & 28 & 25 & 18 & 13 \\
\hline 7 & 35 & 30 & 23 & 16 & 15 \\
\hline 8 & 31 & 29 & 25 & 15 & 12 \\
\hline 9 & 33 & 30 & 25 & 16 & 13 \\
\hline 10 & 35 & 26 & 23 & 15 & 11 \\
\hline 11 & 34 & 29 & 20 & 17 & 15 \\
\hline 12 & 33 & 26 & 24 & 15 & 14 \\
\hline 13 & 31 & 30 & 23 & 19 & 15 \\
\hline 14 & 34 & 28 & 24 & 20 & 12 \\
\hline 15 & 35 & 29 & 25 & 19 & 12 \\
\hline 16 & 30 & 26 & 23 & 20 & 14 \\
\hline 17 & 34 & 30 & 21 & 19 & 11 \\
\hline 18 & 30 & 28 & 22 & 20 & 15 \\
\hline 19 & 35 & 29 & 25 & 15 & 11 \\
\hline 20 & 31 & 28 & 22 & 18 & 12
\end{tabular}

Sumber : Data Transaksi Stockist 319 Padang

Agar masukan dapat dilatih, tabel diubah kedalam bentuk matriks $\mathrm{P}$ berukuran $5 \times 14$ dan data sisanya 
DOI: https://doi.org/10.33330/jurteksi.v7i1.xxx

Available online at http://jurnal.stmikroyal.ac.id/index.php/jurteksi

digunakan untuk pengujian dengan matriks U berukuran $5 \times 6$.

Hasil keluaran (target) yang diinginkan berupa minat konsumen yang terbagi menjadi 2 pola, yaitu Prediksi minat buruk (0) dan Prediksi minat baik (1). Pada pola (0) taksiran antara 0,001 sampai dengan 0,499 dan pola (1) taksiran antara 0,500 sampai dengan 1,000 .

Perancangan Algoritma BackpropagationPelatihan (training) dilakukan untuk memperkenalkan pola-pola atau model-model dari data masukan. Dari 20 Data yang dilatihkan terdiri atas 14 data pada pola keluaran minat buruk (0) dan 6 data pada pola keluaran minat baik (1). Data dilatihkan dengan dipengaruhi oleh model algoritma jaringan yang digunakan, jumlah lapisan tersembunyi, nilai konstanta belajar, besar galat, dan fungsi aktivasi.

Tabel 3. Variabel Input dan target jaringan untuk data pelatihan

\begin{tabular}{|c|c|c|c|c|c|c|}
\hline \multirow{2}{*}{ No } & \multicolumn{5}{|c|}{ Data Input Pelatihan } & \multirow{2}{*}{ Targe } \\
\hline & $\mathrm{X} 1$ & $\mathrm{X} 2$ & X3 & $\mathrm{X} 4$ & $\mathrm{X} 5$ & \\
\hline 1 & 31 & 26 & 20 & 15 & 11 & 1 \\
\hline 2 & 35 & 30 & 25 & 18 & 13 & 1 \\
\hline 3 & 34 & 28 & 23 & 16 & 15 & 1 \\
\hline 4 & 34 & 30 & 24 & 19 & 14 & 1 \\
\hline 5 & 33 & 28 & 23 & 20 & 15 & 1 \\
\hline 6 & 32 & 28 & 25 & 18 & 13 & 1 \\
\hline 7 & 35 & 30 & 23 & 16 & 15 & 1 \\
\hline 8 & 31 & 29 & 25 & 15 & 12 & 0 \\
\hline 9 & 33 & 30 & 25 & 16 & 13 & 0 \\
\hline 10 & 35 & 26 & 23 & 15 & 11 & 0 \\
\hline 11 & 34 & 29 & 20 & 17 & 15 & 0 \\
\hline 12 & 33 & 26 & 24 & 15 & 14 & 0 \\
\hline 13 & 31 & 30 & 23 & 19 & 15 & 0 \\
\hline 14 & 34 & 28 & 24 & 20 & 12 & 0 \\
\hline
\end{tabular}

Variabel input dan target jaringan untuk data Pengujian

Tabel 4. Variabel input dan target jaringan untuk data pengujian

\begin{tabular}{|c|c|c|c|c|c|c|}
\hline \multirow[t]{2}{*}{ No } & \multicolumn{5}{|c|}{ Data Input Pengujian } & \multirow{2}{*}{ Target } \\
\hline & X1 & $\mathrm{X} 2$ & $\mathbf{X 3}$ & $\mathrm{X} 4$ & X5 & \\
\hline 1 & 35 & 29 & 25 & 19 & 12 & 1 \\
\hline 2 & 30 & 26 & 23 & 20 & 14 & 1 \\
\hline 3 & 34 & 30 & 21 & 19 & 11 & 1 \\
\hline 4 & 30 & 28 & 22 & 20 & 15 & 0 \\
\hline 5 & 35 & 29 & 25 & 15 & 11 & 0 \\
\hline 6 & 31 & 28 & 22 & 18 & 12 & 0 \\
\hline
\end{tabular}

Sebelum jaringan dibangun terlebih dahulu dilakukan preproccessing untuk melakukan normalisasi menggunakan mean dan deviasi standar. Apabila data input disimpan pada matriks $\mathrm{p}$, dan target disimpan pada matriks $t$, maka :

[pn,meanp,stdp,tn, meant,stdt] = $\operatorname{prestd}(\mathrm{p}, \mathrm{t})$

Kemudian dibangun jaringan syaraf dengan metode pembelajaran gradient descent dengan momentum (traingdm) :

Net $=$

newff(minmax(pn),[41],\{'tansig','purel in'\},'traingdm');

Tabel 5. Hasil perbandingan Pengujian Akurasi Prediksi Terhadap data uji

\begin{tabular}{cccc}
\hline \multicolumn{2}{c}{ JST 5-2-1 } & \multicolumn{2}{c}{ Kondisi } \\
\hline Hasil & Error & KS & KJST \\
\hline-0.09 & 1.09 & Baik & Salah \\
\hline 2.09 & -1.09 & Baik & Salah \\
\hline 0.32 & 0.68 & Baik & Salah \\
\hline 0.82 & -0.82 & Buruk & Salah \\
\hline 0.34 & -0.34 & Buruk & Benar \\
\hline 0.21 & -0.21 & Buruk & Benar \\
\hline & & & $\mathbf{2 / 4}$ \\
\hline & & & $\mathbf{3 3 . 3 / 6 6 . 7}$ \\
\hline
\end{tabular}


JURTEKSI (Jurnal Teknologi dan Sistem Informasi)

Vol. VI No. 1, Des 2019, hlm. 11 - 18

DOI: https://doi.org/10.33330/jurteksi.v7i1.xxx

Available online at http://jurnal.stmikroyal.ac.id/index.php/jurteksi
ISSN 2407-1811 (Print)

ISSN 2550-0201 (Online)

\begin{tabular}{cccc}
\hline \multicolumn{2}{c}{ JST 5-3-1 } & \multicolumn{2}{c}{ Kondisi } \\
\hline Hasil & Error & KS & KJST \\
\hline 0.33 & 0.67 & Baik & Salah \\
\hline 0.88 & 0.12 & Baik & Benar \\
\hline 0.06 & 0.94 & Baik & Salah \\
\hline-0.34 & 0.34 & Buruk & Salah \\
\hline 0.19 & -0.19 & Buruk & Benar \\
\hline 1.11 & -1.11 & Buruk & Salah \\
\hline & & & $\mathbf{2 / 4}$ \\
\hline
\end{tabular}

33.3/66.7

\begin{tabular}{cccc}
\hline \multicolumn{2}{c}{ JST 5-3-1 } & \multicolumn{2}{c}{ Kondisi } \\
\hline Hasil & Error & KS & KJST \\
\hline 0.33 & 0.67 & Baik & Salah \\
\hline 0.88 & 0.12 & Baik & Benar \\
\hline 0.06 & 0.94 & Baik & Salah \\
\hline-0.34 & 0.34 & Buruk & Salah \\
\hline 0.19 & -0.19 & Buruk & Benar \\
\hline 1.11 & -1.11 & Buruk & Salah \\
\hline & & & $\mathbf{2 / 4}$ \\
\hline
\end{tabular}

$33.3 / 66.7$

\begin{tabular}{cccc}
\hline \multicolumn{2}{c}{ JST 5-4-1 } & \multicolumn{2}{c}{ Kondisi } \\
\hline Hasil & Error & KS & KJST \\
\hline 0.74 & 0.26 & Baik & Benar \\
\hline 1.00 & -0.00 & Baik & Benar \\
\hline-0.13 & 1.13 & Baik & Salah \\
\hline 0.67 & -0.67 & Buruk & Salah \\
\hline-0.04 & 0.04 & Buruk & Salah \\
\hline 1.00 & -1.00 & Buruk & Benar \\
\hline & & & $\mathbf{3 / 3}$ \\
\hline & & & $\mathbf{5 0 / 5 0}$
\end{tabular}

\begin{tabular}{cccc}
\hline \multicolumn{2}{c}{ JST 5-5-1 } & \multicolumn{2}{c}{ Kondisi } \\
\hline Hasil & Error & KS & KJST \\
\hline 0.38 & 0.62 & Baik & Salah \\
\hline 0.88 & 0.12 & Baik & Benar \\
\hline-0.40 & 1.40 & Baik & Salah \\
\hline 0.48 & -0.48 & Buruk & Benar \\
\hline 0.06 & -0.06 & Buruk & Benar \\
\hline 0.69 & -0.69 & Buruk & Salah \\
\hline & & & $\mathbf{3 / 3}$ \\
\hline & & & $\mathbf{5 0 / 5 0}$
\end{tabular}

\begin{tabular}{cccc}
\multicolumn{2}{c}{ JST 5-6-1 } & \multicolumn{2}{c}{ Kondisi } \\
\hline Hasil & Error & KS & KJST \\
\hline 0.26 & 0.74 & Baik & Salah \\
\hline 1.32 & -0.32 & Baik & Salah \\
\hline 0.65 & 0.35 & Baik & Benar \\
\hline 0.89 & -0.89 & Buruk & Salah \\
\hline-0.52 & 0.52 & Buruk & Salah \\
\hline 1.08 & -1.08 & Buruk & Salah \\
\hline & & & $\mathbf{1 / 5}$ \\
\hline & & & $\mathbf{1 6 . 7 / 8 3 . 3}$
\end{tabular}

Hasilnya terlihat pada gambar 1 . berikut

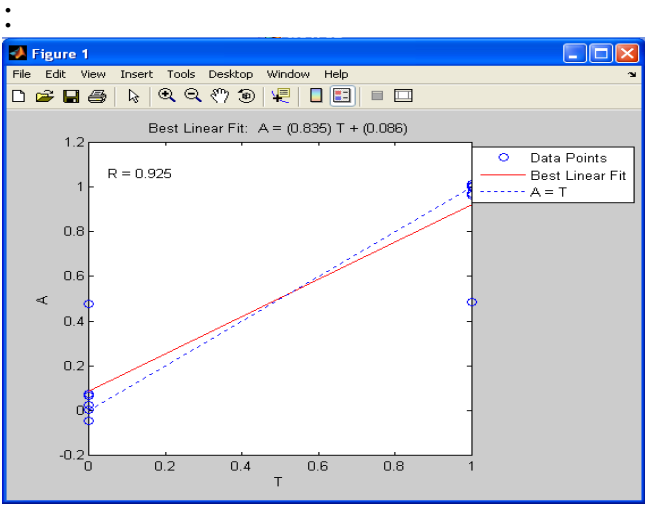

Gambar 1. Perbandingan pelatihan dengan target

Berikut output jaringan dengan target (data pengujian dengan target)

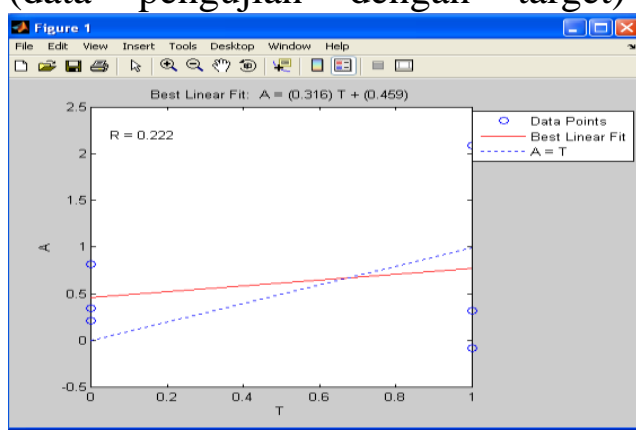

Gambar 2. Perbandingan pengujian dengan target

Selanjutnya untuk melihat hasil pengujian, maka gunakan perintah berikut :>> $\operatorname{plot}([0.01: \operatorname{size}(\mathrm{P}, 2)]$ ',T,'bo',[1:size $(\mathrm{P}, 2)]$ ' ,a','r*');

> title('Hasil Pengujian Dengan Data Pelatihan: Target(o), Output(*)');

>>xlabel('Data

Ke-');ylabel

('Target/Output');pause 
DOI: https://doi.org/10.33330/jurteksi.v7i1.xxx

Available online at http://jurnal.stmikroyal.ac.id/index.php/jurteksi

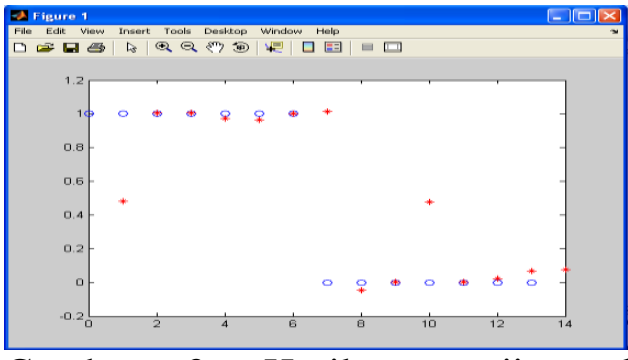

Gambar 3. Hasil pengujian data pelatihan dengan target

Pada gambar 3. terlihat hasil pengujian data pelatihan dengan target. Data ke 2, 3 dan 5 dimana hasil pelatihan sesuai dengan target (1) yang diinginkan dengan nilai aktual 1,00 dan nilai error 0,00 . Nilai ini dapat dilihat setelah dilakukan perintah

$">\quad$ sprintf('\%2d $\% 9.2 \mathrm{f} \quad \% 7.2 \mathrm{f}$ $\left.\% 5.2 \mathrm{f} \backslash \mathrm{n}^{\prime}, \mathrm{H}^{\prime}\right) "$

Berikut ini gambar 4. adalah hasil pengujian dengan data uji(pembanding)

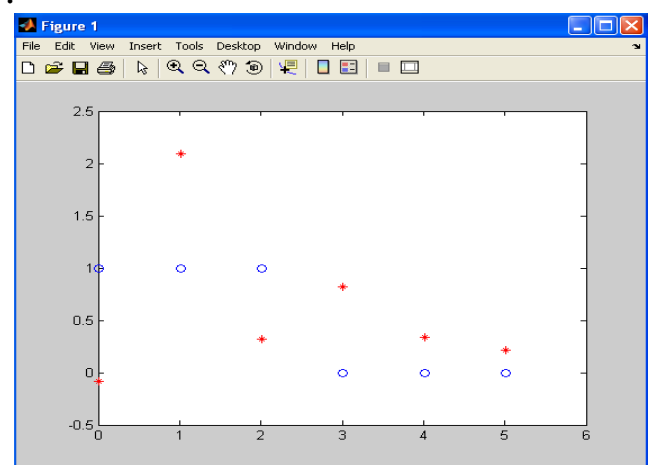

Gambar 4. Hasil pengujian data pembanding (pengujian) dengan target

Pada gambar 4. terlihat hasil pengujian data pembanding (pengujian) dengan target. Data ke 2 dan ke 6 di mana hasil pelatihan sesuai dengan target (0) yang diinginkan dengan nilai aktual 1,00 dan nilai error $-0,00$.

Kesimpulan hasil uji berdasarkan tabel 5.3 :

1. Arsitektur Jaringan 5-2-1

Hasil pembelajaran data ke-5 sesuai dengan target yang diinginkan yaitu 0,97 nilai error tidak ada $(0,03)$. Pada Ketepatan JST (KJST) jumlah benar sebanyak 9 data $(64,3 \%)$, jumlah salah sebanyak 5 data $(35,7 \%)$.

2. Arsitektur Jaringan 5-3-1

Hasil pembelajaran data ke-2 dan 3 sesuai dengan target yang diinginkan yaitu 0,98 nilai error tidak ada $(0,02)$. Pada Ketepatan JST (KJST) jumlah benar sebanyak 8 data $(57,1 \%)$, jumlah salah sebanyak 6 data $(42,9 \%)$.

2. Arsitektur Jaringan 5-4-1

Hasil pembelajaran data ke-4 sesuai dengan target yang diinginkan yaitu 0,92 nilai error tidak ada $(0,08)$. Pada Ketepatan JST (KJST) jumlah benar sebanyak 6 data $(42,9 \%)$, jumlah salah sebanyak 8 data $(57,1 \%)$.

3. Arsitektur Jaringan 5-5-1

Hasil pembelajaran data ke-3 dan 4 sesuai dengan target yang diinginkan yaitu 0.99 dan 0.99 nilai error tidak ada $(0,01)$. Pada Ketepatan JST (KJST) jumlah benar sebanyak 9 data $(64,3 \%)$, jumlah salah sebanyak 5 data $(35,7 \%)$.

4. Arsitektur Jaringan 5-6-1

Hasil pembelajaran data ke-2 sesuai dengan target yang diinginkan yaitu 0,98 nilai error tidak ada $(0,02)$. Pada Ketepatan JST (KJST) jumlah benar sebanyak 7 data (50\%), jumlah salah sebanyak 7 data (50\%).

Kesimpulan hasil uji berdasarkan tabel 5.4 :

1. Arsitektur Jaringan 5-2-1

Hasil pengujian data ke-3, mendekati target yang diinginkan yaitu 0,32 , dan nilai error tidak ada $(0,68)$. Pada Ketepatan JST (KJST) jumlah benar sebanyak 2 data $(33,3 \%)$, jumlah salah sebanyak 4 data $(66,7 \%)$.

2. Arsitektur Jaringan 5-3-1

Hasil pengujian data ke-2, mendekati target yang diinginkan yaitu 0,88 nilai error $(0,12)$. Pada Ketepatan JST (KJST) jumlah benar sebanyak 2 data $(33,3 \%)$, jumlah salah sebanyak 4 data $(66,7 \%)$. 
DOI: https://doi.org/10.33330/jurteksi.v7i1.xxx

Available online at http://jurnal.stmikroyal.ac.id/index.php/jurteksi

\section{Arsitektur Jaringan 5-4-1}

Hasil pengujian data ke-2, mendekati target yang diinginkan yaitu 1.00 nilai error (-0.00). Pada Ketepatan JST (KJST) jumlah benar sebanyak 3 data (50\%), jumlah salah sebanyak 3 data $(50 \%)$.

\section{Arsitektur Jaringan 5-5-1}

Hasil pengujian data ke-2, mendekati target yang diinginkan yaitu 0,88 nilai error $(0,12)$. Pada Ketepatan JST (KJST) jumlah benar sebanyak 3 data (50\%), jumlah salah sebanyak 3 data $(50 \%)$.

5. Arsitektur Jaringan 5-6-1

Hasil pengujian data ke-3, mendekati target yang diinginkan yaitu 0,65 nilai error (0,35). Pada Ketepatan JST (KJST) jumlah benar sebanyak 1 data $(16,7 \%)$, jumlah salah sebanyak 5 data $(83,3 \%)$.

\section{SIMPULAN}

Jaringan Syaraf Tiruan dapat digunakan untuk memprediksi minat konsumen Stockist 319, berdasarkan tingkatan konsumen terhadap produk yaitu sangat suka, suka, biasa, tidak suka dan tidak tahu.

\section{DAFTAR PUSTAKA}

[1]Safik Ritonga, suryo Atmojo, "Pengembangan model jaringan syaraf tiruan untuk memprediksi jumlah mahasiswa baru di PTS surabaya", Vol.12, No. 1, Tahun 2018.

[2]Aulia Yudha Prathama, Akhmad Aminullah, Ashar Saputra, "Pendekatan ANN(Artificial Neural
Network) untuk penentuan prosentase bobot pekerjaan struktur pada rumah sakit pratama", VOL 7, NO.1, DESEMBER 2017; 14-25, DOI 10.22146/teknosains.30139, https://jurnal.ugm.ac.id/teknosains.

[3]Dimas Fajar Latif Maulana, "Aktivitas promosi dalam pemasaran smart", Artikel Publikasi.

[4]EV Hanifah, Sukarelawati, Agustini, "Metode promosi melalui direct selling dalam meningkatkan minat konsumen menggunakan jasa hotel", Volume 3 Nomor 1, April 2017

[5]Ferdian, Edwar, Pembangunan Perangkat Lunak Prediksi Harga Saham dan Indeks, Tesis, Sekolah Teknik Elektro dan Informatika, Institut Teknologi Bandung, Bandung, 2007

[6]Hendri Cahya Aprilianto, Sri Kumalaningsih dan Imam Santoso, "Penerapan Jaringan Syaraf tiruan untuk peramalan penjualan dalam mendukung pengembangan Agroindustri coklat di kabupaten bliter, DOI: 10.21776/ub.habitat.2018.029.3.16, ISSN: 0853-5167 ; 2338-2007

[7]Laila Sari Lubis, Agus Buono, "Pemodelan jaringan syaraf tiruan untuk memprediksi awal musim hujan berdasarkan suhu permukaan laut", Volume 1 Nomor 2 Halaman 52- 61, ISSN: 2089-6026, http://journal.ipb.ac.id/index.php/jika [8]Luh Mirayani, "Analisis penerapan strategi direct selling dan dampaknya terhadap volume penjualan pada PT.Karya Pak Oles tokce di desa bengkel tahun 2016", Volume: 10 No: 2 Tahun: 2017. 